\title{
EL LICEO DE LOGROÑO (1868): LOCALIZACIÓN DE UN NUEVO ESPACIO TEATRAL
}

\section{Julián Bravo Vega y Francisco Domínguez Matito}

Universidad de La Rioja

\section{CUESTIONES PREVIAS: UBICACIÓN, RELACIÓN DE PROPIETARIOS Y USOS POSTERIORES}

En la logroñesa calle de la Ruavieja, a medio centenar de metros de la embocadura cercana al Puente de Piedra, se halla hoy un inmueble registrado con el número $42^{1}$. En su interior, como si fuera un espacio suspendido en el tiempo, se encuentra, prácticamente intacto, el teatro del Liceo. Su construcción, de nueva planta, se remonta a 1868 , pero su actividad escénica pronto quedó limitada por la competencia de nuevos teatros logroñeses, más aptos y capaces, como el Quintana (1880) o Principal, llamado desde 1901 Bretón de los Herreros, y el

\footnotetext{
1 Véase Plano de zona (figura 1) en la sección de Apéndices.
} 
Zaporta (1912), conocido después como Moderno. Tras su postergación, cayó en desuso y, finalmente, fue adaptado a actividades comerciales, en cuyo acondicionamiento sufrió diversas modificaciones y reformas que en nada afectaron a su disposición original. En la actualidad no cumple usos comerciales y su función queda reducida a la de simple cochera de los vehículos de la Panificadora Berceo, situada en Ruavieja 44. El teatro del Liceo posee, no obstante, una larga historia como inmueble. Empecemos desde el principio.

El 28 de mayo de 1868 se reúnen en Logroño dos comerciantes, José Pueyo Viñas y Pedro Ramos Rodríguez. El primero vende al segundo cuatro fincas urbanas de su propiedad. Las tres primeras son casas contiguas de la calle Mayor que lindan a su espalda, o norte, con un «jardín que era de la misma casa y ahora el local Liceo de esta ciudad, que se está construyendo y está para terminarse». La tercera «consta sólo la casa del piso firme, que se ha hecho un gran salón de descanso en lo que ocupaba antes el portal, lagos y corral de dicha casa, y sirve de entrada y paso para el local Liceo. Éste se halla a la espalda de dichas casas en lo que era antes jardín. Y linda por el norte otra casita edificada también en la que era antes jardín y que da a la calle de San Gregorio [...] Tiene la casa mencionada descrita seis metros y veinte y dos centímetros de frente, y de largo, con el salón de descanso, veinte y ocho metros y cincuenta centímetros. El local del Liceo tiene de largo veinte metros, y de anchura once metros y veinte y cinco centímetros, el valor de dicha casa, incluso el edificio Liceo, es el de tres mil escudos». La cuarta finca, «una casita sita en la calle de San Gregorio [...] número trece», ya ha sido descrita someramente. Con el tiempo la calle de San Gregorio se convertirá en Ruavieja y la «casita» en dependencia anexa al Liceo, hoy Panificadora Berceo.

Las tres primeras casas las ha comprado Pueyo a los herederos de Manuel Cuartango el 2 de diciembre de 1855 y todavía cargan con censos a favor de la iglesia colegial de la Redonda y de la de Santa María de Palacio, próxima ésta a las casas, mientras que «el local Liceo y casita de la calle de San Gregorio» son de nueva planta. José Pueyo Viñas, el vendedor, tasa las casas y el Liceo en 6.200 escudos, se reserva durante los cinco años siguientes el derecho de retroventa, que no ejercerá, y «se obliga a pagar el importe de las obras que se estan ejecutando en el local Liceo y que tiene contratadas con arreglo al proyecto o contrato de arriendo celebrado con la Junta del Liceo y que están ya para terminar, de modo que el comprador ha de recibir dicho local y salón de descanso o paso a él, concluidas dichas obras en 
la forma convenida en el arriendo con la Junta del Liceo...». Además, el comprador, Pedro Ramos, «ha de respetar el contrato de arriendo que tiene hecho con la Junta del Liceo por el tiempo de cuatro años de dicho local Liceo bajo las mismas condiciones y precio que constan en el documento privado sucrito por dicha Junta y el D. José Pueyo, que tiene conocimiento D. Pedro Ramos» ${ }^{2}$.

De todo ello resulta que a la calle de San Gregorio, después Ruavieja, se orientan el Liceo y una casita, que desplazándose hacia el sur existe un patio, común al Liceo y a las casitas, y que el bajo de una de las casas es, a la vez que salón de descanso, corredor de comunicación con la calle Mayor, lugar de acceso para el público. La entrada de San Gregorio queda reservada para uso particular de los que intervienen en las funciones $\mathrm{y}$, como se verá después, del aposentador del local, cuya vivienda, dispuesta en la cabecera del Liceo, comunicará directamente con la calle de San Gregorio. El espacio teatral y sus accesos quedan, pues, perfectamente definidos y la documentación permite establecer la relación exacta entre el propietario de los inmuebles y la Junta del Liceo.

Pedro Ramos Rodríguez fallecerá el 6 de febrero de 1884, dejando como heredera única a su hija Inicencia Ramos, de 19 años, casada con Perfecto García Jalón. Las casas, el paso y el Liceo se hallan perfectamente registradas en el inventario de bienes del difunto, pero la casita de San Gregorio ha aumentado en su fachada desde 6,20 a 11,25 metros ${ }^{3}$. Ello se ha debido a que se ha contabilizado como finca única toda la fachada de la calle San Gregorio, la que pertence al Liceo (es decir, la casa del aposentador) y la propia de la «casita» anexa.

Cuando el Liceo deja de tener utilidad como recinto teatral, la agrupación de fincas (que ha producido una finca amillarada) se deshace y se producen las segregaciones. La «casita de San Gregorio, 13» es vendida el 25 de noviembre de 1909 a Domingo Rico y Calderón. Para entonces ya ha sido segregada del conjunto y corresponde al número 68 de la Ruavieja. En el momento de la venta «consta de tres lagos, cuadra y prensa en la parte baja, un pequeño entresuelo, dos pisos y desván» ${ }^{4}$. El 12 de junio de 1911 es adquirida por Agapito Rodríguez

2 Archivo Histórico de La Rioja (A.H.L.R.). Protocolos. Plácido Aragón (1868). Legajo 7.746.

3.H.L.R. Protocolos. Plácido Aragón (1884). Legajo 8.568.

4 Colegio Notarial de Burgos. Notaría de Antonio Pérez Fernández, de Logroño. Compra-venta de dos casas por Domingo Rico Calderón, el 25 de noviembre de 1909. 
Díez ${ }^{5}$. El 16 de mayo de 1930 pasa a poder de Hipólito Berceo Ramírez ${ }^{6}$, quien la habilita para la industria Panificadora Berceo. En la actualidad es regentada por su yerno, Máximo Fernández Martínez, para los mismos usos.

Por su parte, el número 66 de Ruavieja queda constituido por dos cuerpos, que son la casa del aposentador, situada en el piso superior de la cabecera del Liceo, y por el propio Liceo en sí. A la casa se accede desde el interior, por una escalera situada a la derecha de la entrada. La planta baja posee portal de entrada y dos cuadras, y el piso dispone de habitaciones con ventanas tanto a la calle como al propio Liceo; el cuerpo posterior queda «integrado por un local de planta baja donde estaba el antiguo Liceo». Inocencia Ramos ha vendido el inmueble a José Llach Latorre, quien el 9 de marzo de 1928 lo vende a los hermanos Rafael, Casimiro y Miguel Miguel Benito ${ }^{7}$. La segregación definitiva de las tres casas de la calle Mayor (ahora números 163, 165 y 167), que seguirán perteneciendo a Llach, se produce el 2 de enero de 1932. La finca de Ruavieja 66, propiedad de los hermanos Miguel, queda independizada y es descrita, con no demasiada exactitud, como una «superficie de 83,60 de dos plantas y una superficie de 202,40 destinado a cocheras». Las casas de la calle Mayor pasan de Perfecto García Jalón, el marido de Inocencia Ramos, a Llach y a múltiples propietarios que llegan hasta nuestros días ${ }^{8}$. Las casas empiezan a deteriorarse y los inquilinos elevan frecuentes denuncias sobre su mal estado e, incluso, amenaza de ruina. El Ayuntamiento de Logroño acaba comprando o permutando las fincas de la calle Mayor (ahora Marqués de San Nicolás) en 1992 y el arquitecto municipal inicia expediente urgente de ruina, que completa en un mes. El derribo se adjudica a Juan Pérez Asenjo en diciembre de 1993 y se ha concluido en mayo de 1995. En la actualidad es un solar vallado, cerrado al público por tabiquería y puertas metálicas, desde el que se accede directa y visualmente a las traseras del Liceo. Queda un pequeño paño de fachada, en el que se reconocen los pilares y el dintel de la puerta de Marqués

5 Colegio Notarial de Burgos. Notaría del Licenciado en Derecho D. Nicolás Rodríguez y Temiño. Logroño. Compra-venta de casa en esta ciudad, calle de la Ruavieja, n. ${ }^{\circ}$ 68, precio 2.000 pts., otorgada por D. Domingo Rico Calderón a favor de D. Agapito Rodríguez Díez en 12 de junio de 1911.

6 Colegio Notarial de Burgos. Notaría de D. Enrique de Mora Arenas. Logroño. Compra-venta por D. Agapito Rodríguez Díez a favor de D. Hipólito Berceo Ramírez, en 16 de mayo de 1930.

7 A.H.L.R. Sección Hacienda. Caja 8699. Ruavieja 66.

8 A.M.L. 184/52, 188/4. A.M.L. IGE. 424/35. 
Nicolás, 20, o aquélla por la que accedía el público desde la calle Mayor al Liceo.

Volviendo al número 66 de Ruavieja, la finca sufrirá diversas reformas para adaptarla a nuevas necesidades comerciales. En 1928, Jerónimo Miguel modifica la morfología de la fachada para atender a un negocio de pompas fúnebres. La única puerta se agranda para permitir el acceso de carruajes, la ventana de poniente se convierte en puerta de acceso a la vivienda superior y el balcón central superior, en estado ruinoso, pasa a ser mirador. Los cambios también afectan al interior. Desde la puerta central se construye una rampa para facilitar el paso de carruajes mortuorios y los espacios laterales se habilitan para establo y guardarnés. Se suprime el acceso interior a la vivienda ${ }^{9}$. Hacia 1935 se hace cargo del local la Funeraria Pastrana. Pasa después a poder de Miguel Ruiz de Palacios, quien en 1946 traslada a este local la chatarrería-trapería de su propiedad que se halla situada en la misma Ruavieja, n. ${ }^{\circ} 85$; esgrime como razones su gran capacidad y su inmejorable ventilación ${ }^{10}$. Luis Díaz Ruiz, nuevo propietario, mantiene en principio el almacén de chatarrería, para después sustituirlo por otro de mayor capacidad en el cercano Camino de las Norias, 18, bajo el nombre de Recuperaciones Díaz. En 1962, Luis Díaz pide permiso para reformar el mirador, que amenaza ruina ${ }^{11}$. En 1981 es mero pabellón de depósito de Recuperaciones Ruiz, mientras que la vivienda superior se halla alquilada. Al desprenderse parte del alero del edificio y caer sobre la calle, el arquitecto municipal indica en su informe que «la parte posterior consta de una nave (antiguo teatro), destinada actualmente a la recogida y empaquetado de papelería» ${ }^{12}$. En la actualidad conserva restos de chatarra, envases de vidrio, forjados de papel y cartonaje. Su propietario sigue siendo Luis Díaz Ruiz, domiciliado en Zaragoza, pero su uso corresponde a la Panificadora Berceo de Logroño, regentada, como queda dicho, por Máximo Fernández Martínez. La panadería se halla ubicada en el local contiguo de

9 Archivo Municipal de Logroño (A.M.L.). Inventario General de Expedientes. Exp. 442/18. Jerónimo Miguel, Ruavieja 66, C. Se conservan planos del arquitecto Quintín Bello, fechados el 24-1-1928, que recogen el estado actual y la propuesta de transformación. La reforma del mirador, proyectada por el mismo arquitecto, es de 248-1928.

10 A.M.L. Policía Urbana (P.U.). Exp. 50/46. Miguel Ruiz de Palacios. Ruavieja 66.

11 A.M.L. Ref. P.U. Exp. 949/62. Luis Díaz Ruiz, sustituir mirador por balcón en estado ruinosos. Ruavieja 66.

12 A.M.L. Ref. P.U. Exp. 762/81. Informe arquitecto por desprendimiento parte medianil, Ruavieja 42. 
Ruavieja 44 (o antigua casita de San Gregorio). El patio teatral del Liceo sirve actualmente de cochera a los vehículos de la panadería.

\section{EL ESPACIO TEATRAL}

El actual acceso al Liceo se hace por Ruavieja 42, antaño entrada reservada para el servicio del local y usos profesionales. La fachada que se observa procede de una reforma de 1928, realizada para convertir el local en empresa funeraria. Con tal motivo, la única puerta se ensancha para permitir el paso de carruajes y la ventana oeste se convierte en puerta para dar a la vivienda superior acceso independiente. Una vez que se entra en el local, nos encontramos con una pequeña rampa a modo de corredor; a ambos lados existen dos espacios, restos de establos y de guardarnés. Sobre esta superficie se encuentra la casa del aposentador o encargado del teatro, de una altura y ático. La rampa facilita el acceso al patio, que en su muro oeste posee una escalera precaria para subir a un rústico anfiteatro (gallinero) y, centrada en la fachada sur, se observa la puerta de acceso al público. La superficie total de la planta es de 25 metros de largo por 11 de ancho aproximadamente, mientras que la del patio es de unos 275 metros útiles. La plataforma que se eleva sobre el patio para constituir el anfiteatro está a $3,79 \mathrm{~m}$. sobre el piso llano y ocupa una superficie inferior a $80 \mathrm{~m}$.

Dirigiéndonos al muro norte, observamos que posee tres ventanas, comunes a la casa del aposentador, que sirven tanto a efectos escénicos como visuales. A la altura del ático existe un amplio balcón, corrido a lo largo de tres cuartas partes de la anchura hacia el este. Su uso se justifica tanto por razones escénicas (manipulación de tramoya y decorados) como para albergar a la orquesta en veladas musicales. Todo ello confirma que el tablado escénico había de elevarse sobre el suelo y apoyarse en este muro. Como es de esperar por los usos posteriores del local, no queda ningún resto de él, aunque ciertos huecos en la pared, a modo de anclajes, parecen recordar su disposición y altura. Por su parte, el muro sur presenta dos niveles de ventanas sobre el anfiteatro, que recogen la abundante luz del mediodía y la proyectan en el norte, menos iluminado, donde se halla la escena. La ausencia actual de edificación posterior hace que la luz sea muy abundante, a pesar de estar tapiadas algunas de sus ventanas. Un techo airoso, sostenido por vigas tramadas a modo de cercha o tijera, permite crear una bóveda interior 
que facilita el paso de la luz y contribuye a la luminosidad del edificio. Las vigas están unidas horizontalmente por tirantes metálicos, que se regulan con tensores centrales para repartir y equilibrar la tensión de la techumbre sobre los muros. Dos luceras o claraboyas rectangulares proyectan luz cenital, aumentando la luz sobre el patio.

Si los elementos anteriores son absolutamente perceptibles, existen otros que, por no haberse conservado, son de más dudosa valoración. Destacan, en primer lugar, unos rebajes sobre dos pilares de obra del muro oeste, que por su disposición parecen sustentar un balcón corto, a modo de palco pequeño o galería reducida, destinado a invitados ilustres. Hubo de disponer de acceso propio. Aproximadamente a la misma altura, pero en el muro opuesto, se aprecia una serie de anclajes que, partiendo del anfiteatro, llegan al muro norte. Se trata de una serie de escuadras que sostienen la base de una galería corrida, a modo de palco, que algunos testigos recuerdan haber visto. En la intersección entre el anfiteatro y la galería se halla una rectificación sobre la obra del muro (oeste) que parece corresponder a una gran puerta de acceso, posteriormente tapiada. Ello llevaría a la hipótesis de que la casa contigua, que es la Panificadora Berceo (recuérdese que corresponde a la antigua «casita de San Gregorio», anexa en origen al Liceo), formaba conjunto con las dependencias teatrales. La casa disponía de un zaguán de entrada, a modo de distribuidor, desde donde se accedía a una sala corrida de norte a sur, paralela al Liceo y contigua a su muro oeste, y a unas escaleras que llevaban al piso superior; allí una puerta facilitaba la comunicación con la galería del Liceo. Una de las varias reformas que Anastasio Berceo somete a la casa consiste en dividir el portal e independizar el obrador de panadería del acceso a la vivienda ${ }^{13}$. Sin embargo, la puerta exterior posee la misma morfología que la del Liceo, con idénticos adornos en el dintel. A pesar del parteluz que la divide en la actualidad, se observa que las dos puertas se han construido con los mismos criterios. De confirmarse esta hipótesis, la casa serviría de sala anexa a la Sociedad Artística y Literaria Riojana, a la vez que de acceso a la galería; el recinto del Liceo quedaría reservado para usos artísticos, mientras que la sala permitiría las reuniones de la Sociedad. Por otra parte, la escalera que comunica actualmente el patio del Liceo con el anfiteatro es muy estrecha y empinada, con peldaños incómodos y peligrosos para un ascenso frecuente, sin restos de barandilla y pasamanos, por lo que

13 A.M.L. Exp. 282, año 1939. Reforma de la vivienda del piso 3. ${ }^{\circ}$ Exp. 204, año 1946. Reformas en el portal. Exp. 136, año 1944. Derrumbamiento de la cubierta. Exp. 163, año 1944. Transformación de la bajocubierta en un piso ático, abuhardillado, con terraza. 
difícilmente pudo ser la escalera original. Una vez segregadas ambas fincas, el acceso a la zona superior desapareció y fue necesario buscar una comunicación desde dentro, recurriendo a una escalera convencional, pues no precisaba de uso público. El estado del local, repleto de restos que provienen del almacén de chatarra y trapería, no permite realizar las comprobaciones oportunas, pero los indicios apuntan en la dirección marcada.

Con respecto a la arquitectura del edificio, hay que señalar que se trata de espacio de transición desde el corral de comedias de la Misericordia, que se halla a unos doscientos metros en línea recta, a los coliseos modernos, como el teatro Quintana. La Sociedad Artística y Literaria Riojana, que regenta el corral hasta mediados de siglo, debe ceder su espacio para usos internos del Hospital Civil, pues se halla ubicado en el interior del recinto hospitalario. Madoz (1985: 140-1) nos confirma este extremo: «El teatro [...] ocupa una parte del establecimiento. Se entra por la misma puerta del Hospital y aún se sube a los palcos por la escalera que bajan los difuntos. Su mala situación y falta de comodidad no retraen la concurrencia, y es sensible no se trate de habilitar para tan importante objeto otro edificio más sólido y mejor situado».

El patio de comedias (de La Misericordia o de Roque Amadoz) data de tiempos de Felipe IV y en el siglo XIX no sólo es inadecuado, sino que colisiona con los usos propios del Hospital. Por eso, hacia 1850 , como el consistorio logroñés proyecta construir un coliseo municipal, pero no hacer frente a sus costes, la Sociedad Artística y Literaria Riojana, que gestiona el patio y destina sus beneficios al sostén del Hospital, toma la iniciativa de alquilar -que no de construir, porque es público que el Ayuntamiento logroñés lleva varios años intentando elevar teatro propio (Cerrillo Rubio, 1993: 86-98) — un local destinado a teatro de transición, a la vez que a sala de usos culturales, pues, a la postre, es el único espacio específico que posee la ciudad para estos fines.

El Liceo nace, pues, con el objetivo de cubrir el vacío cultural del patio de comedias y, a la vez, con la necesidad de convertirse en espacio escénico polivalente mientras llega el teatro definitivo, tantas veces anunciado. Por ello, en la construcción se observa ese aire de provisionalidad que se desprende de lo que no se planifica con una idea marcada o definitiva. Posee, por una parte, rasgos propios de los patios de comedias, como espacio reducido, arquitectura austera y funcional que avanza hacia una techumbre recia y airosa, carece de elementos super- 
fluos u ornamentales (v. gr., perceptible en los restos que quedan de una barandilla original, muy pobres y con atoques listados), no hay indicios de utilización de tramoya complicada, los espacios destinados al público cubren estrictamente sus fines y, en fin, su aforo no rebasaría las cuatrocientas localidades. Existen también rasgos de aproximación a los teatros de la segunda mitad del XIX, como modesto anfiteatro (gallinero) y atisbos de palcos. Por otra parte, se acentúa su concepción polivalente, apta tanto para una representación teatral como para una velada musical, bailes, reuniones y los mil usos que puede soportar el único salón de estas características en Logroño desde 1868 hasta 1880 . El balcón sobre la escena, con cabida para la orquesta, muestra esa versatilidad. Por todo ello, el espacio teatral oscila entre el corral de comedias y lo que después serán los coliseos modernos. En esa transición, tan rara de encontrar, porque su condición ecléctica y modesta suele llevar a este tipo de edificios al derribo, se hallan las singularidades del Liceo.

\section{A MODO DE CONCLUSIÓN}

A pesar del tiempo transcurrido desde su construcción, de los variados usos, de las continuas reformas, el teatro del Liceo mantiene un estado de conservación muy aceptable. Su fisonomía actual permite reconocer a simple golpe de vista sus antiguos usos. Con el paso del tiempo se ha convertido en el espacio escénico más antiguo de entre los conservados en Logroño, sólo precedido en el tiempo por el corral de comedias del Hospital de la Misericordia, cuya actividad llegó hasta mediados del siglo XIX (Domínguez Matito, 1998).

Su importancia es, pues, capital para la historia de Logroño, que por aquellas fechas de 1868 (año que corresponde a la Gloriosa), empieza a caminar desde el Antiguo Régimen hacia la Restauración, cambia su urbanismo y acomete nuevas y diversas construcciones, cuya recopilación muestra I. Cerrillo (1993: 99-103). La edificación del Liceo se halla dentro de ese modelo de transformación de la ciudad que acontece con el espíritu de la Gloriosa y del que es representante cualificado D. Práxedes Sagasta. No en vano el Liceo será visitado en 1973 por Amadeo I, en velada a la que asiste Espartero ${ }^{14}$.

14 A.M.L. Actas Capitulares, 1981, fols. 94v-102. 
Nuestra intención desde estas líneas, precursoras de un estudio más complejo sobre la Sociedad Artística y Literaria Riojana y la cultura teatral logroñesa de la segunda mitad del siglo XIX, es rescatar este teatro olvidado ${ }^{15}$, valorar su contribución al desarrollo de la historia cultural de Logroño durante la segunda mitad del siglo XIX y sugerir su inmediata incorporación al catálogo histórico y monumental de bienes patrimoniales de La Rioja. Lo que en adelante pudiera ocurrirle al Liceo excede nuestra competencia y queda sometido a la responsabilidad exclusiva de las autoridades culturales y políticas de La Rioja y al conjunto de los poderes públicos del país. Sirven las páginas de esta revista como muestra de la implicación social del medio universitario y como llamada de atención sobre nuestro patrimonio cultural.

\section{Referencias bibliográficas}

CERRIllo Rubio. I. (1993). «Arquitectura del ocio». En La formación de la ciudad contemporánea. Logroño entre 1859 y 1936. Desarrollo urbanístico y tipologías arquitectóricas. Logroño: I.E.R.

DomíngueZ MatrTo, F. (1998). El teatrto en La Rioja: 1580-1808. Los patios de comedias de Logroño y Calahorra. Estudio y documentos. Logroño: Universidad de La Rioja.

MADOZ, P. (1985). Diccionario Geográfico-Estadístico-Histórico de España y sus posesiones de Ultramar. Rioja. Logroño: Gráficas Ochoa.

\section{Apéndices}

1. Plano de zona.

2. Sección transversal proyectada sobre el muro este.

3. Sección interior de la fachada este (izquierda) y oeste (derecha).

4. Planta baja.

5. Planta piso.

15 Véanse referencias de prensa en La Rioja, 17 oct. y 1 nov.; El Correo, 17, oct., 28 oct. 1998. 
EL LICEO DE LOGROÑO (1868): LOCALIZACIÓN DE UN NUEVO ESPACIO TEATRAL

6. Planta superior.

7. Ilustraciones.

7.1. Calle Ruavieja, 42. Fachada exterior del Liceo.

7.2. Techumbre de madera.

7.3. Detalle del muro sur.

7.4. Detalle del muro norte. 


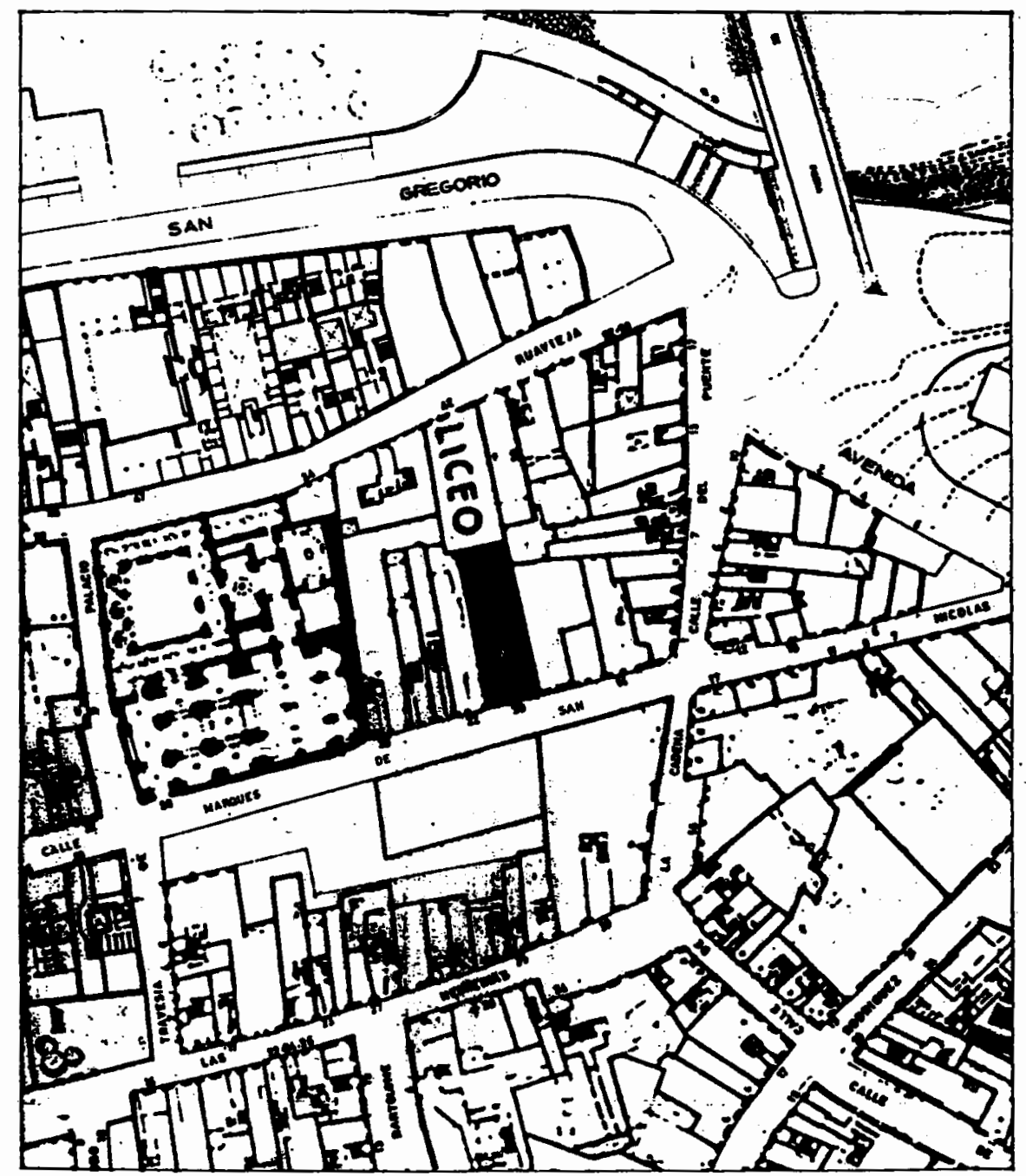

Plano de zona. 


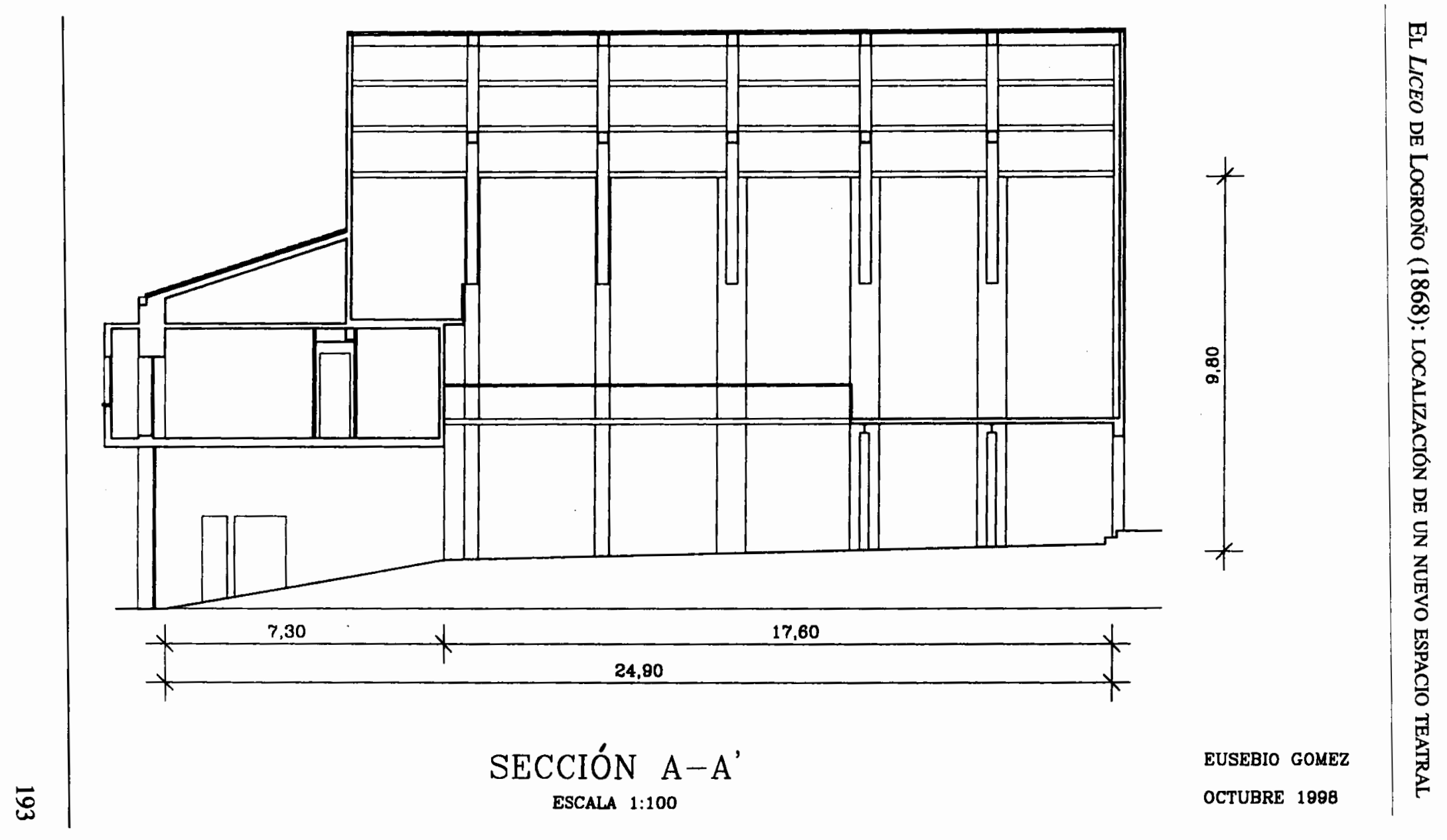



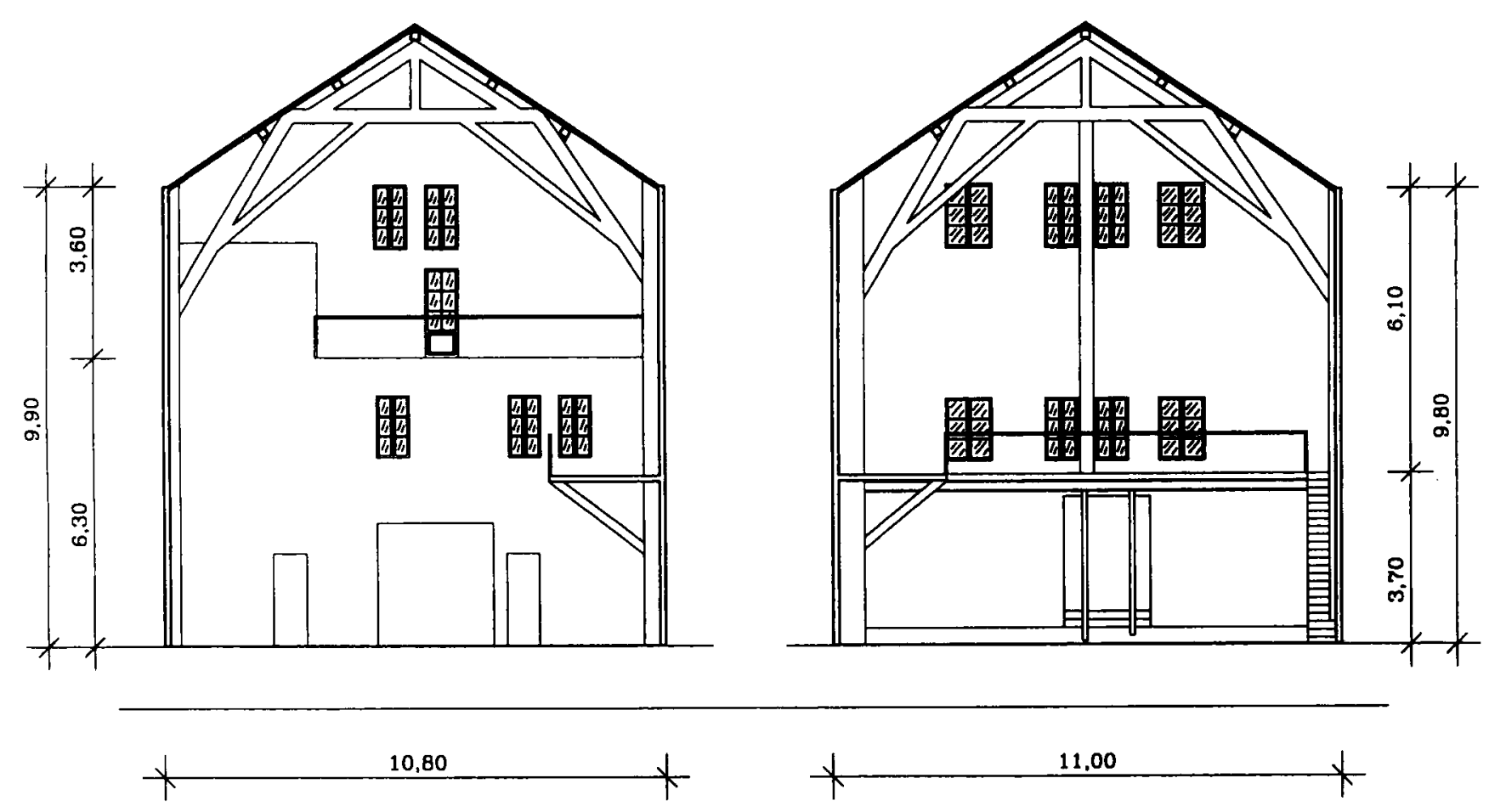

忌

SECCION B-B'

SECCION C-C'.

EUSEBIO GOMEZ

ESCALA 1:100

ESCALA 1:100 


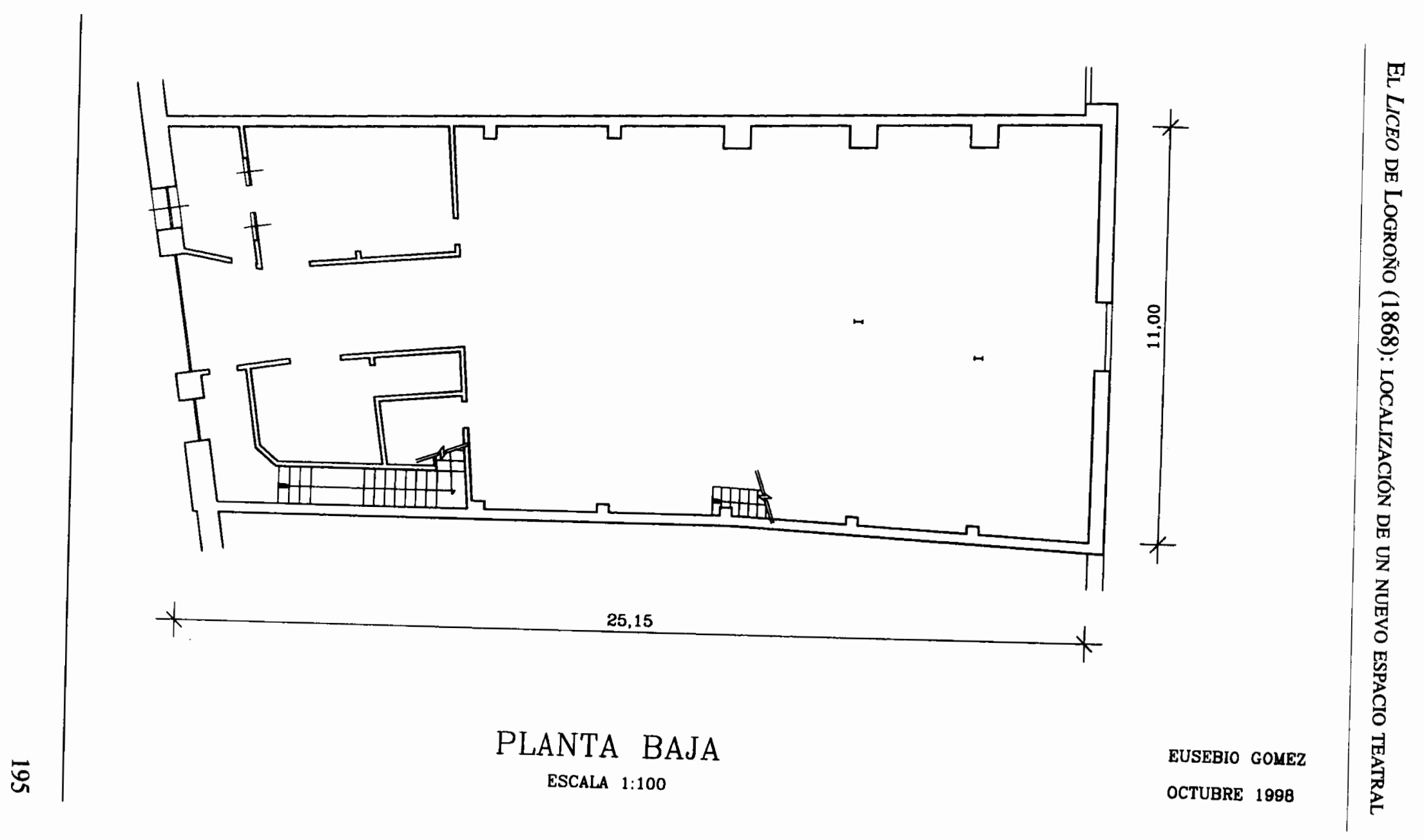


కू

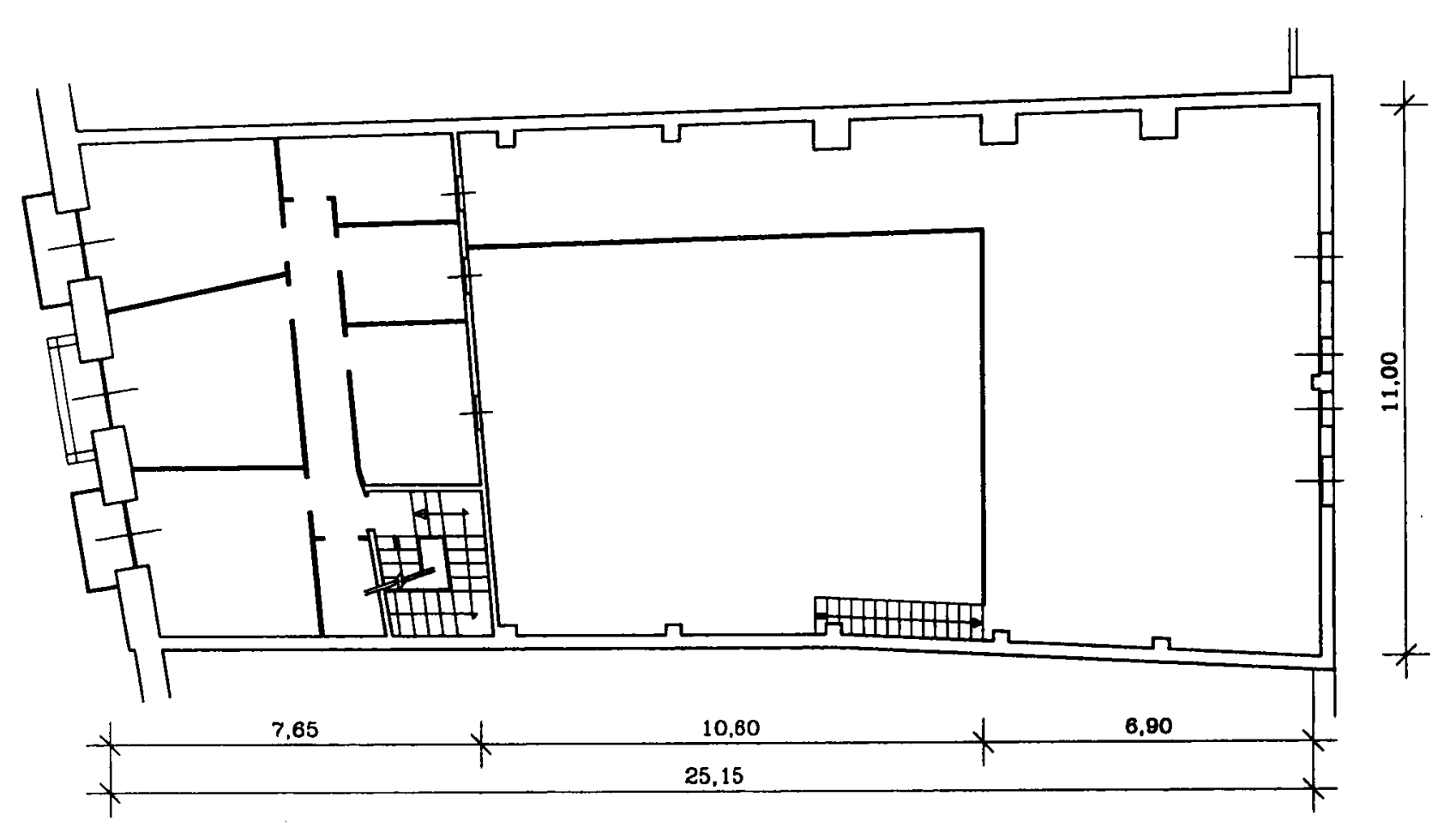

PLANTA PISO 


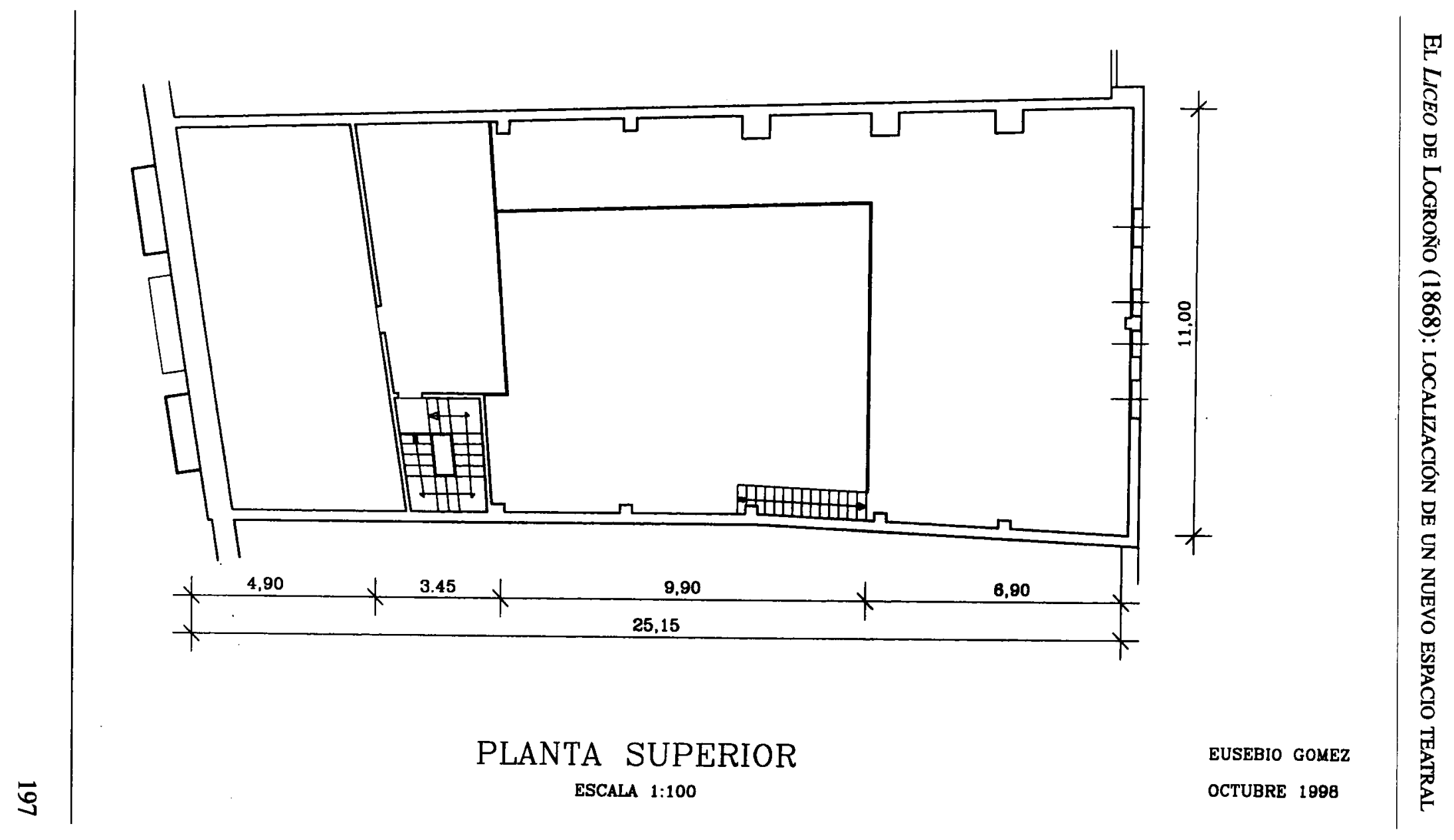




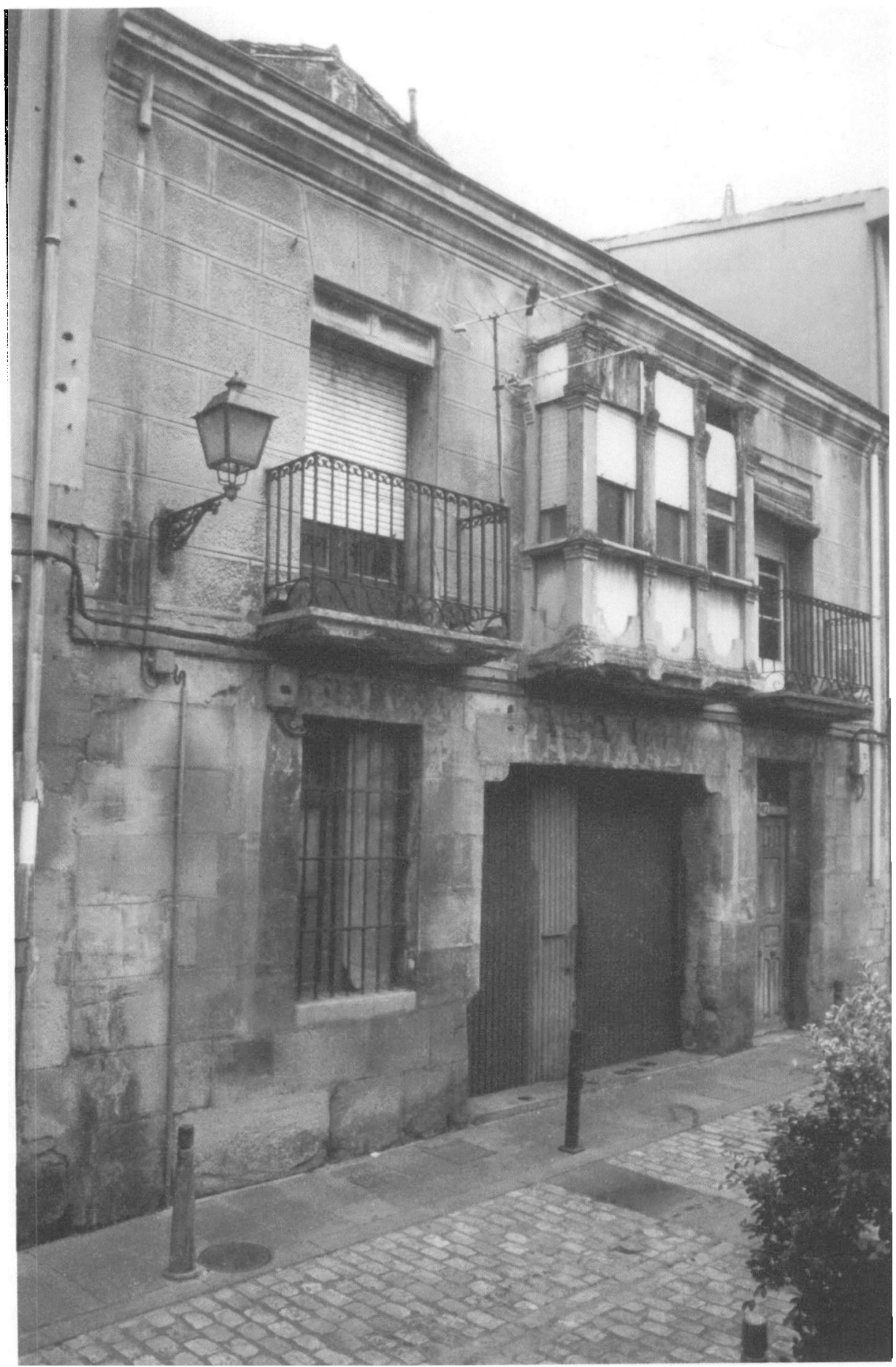

7.1. Calle Ruavieja, 42. Fachada exterior del Liceo. 
EL LICEO DE LOGROÑo (1868): LOCALIZACIÓN DE UN NUEVO ESPACIO TEATRAL

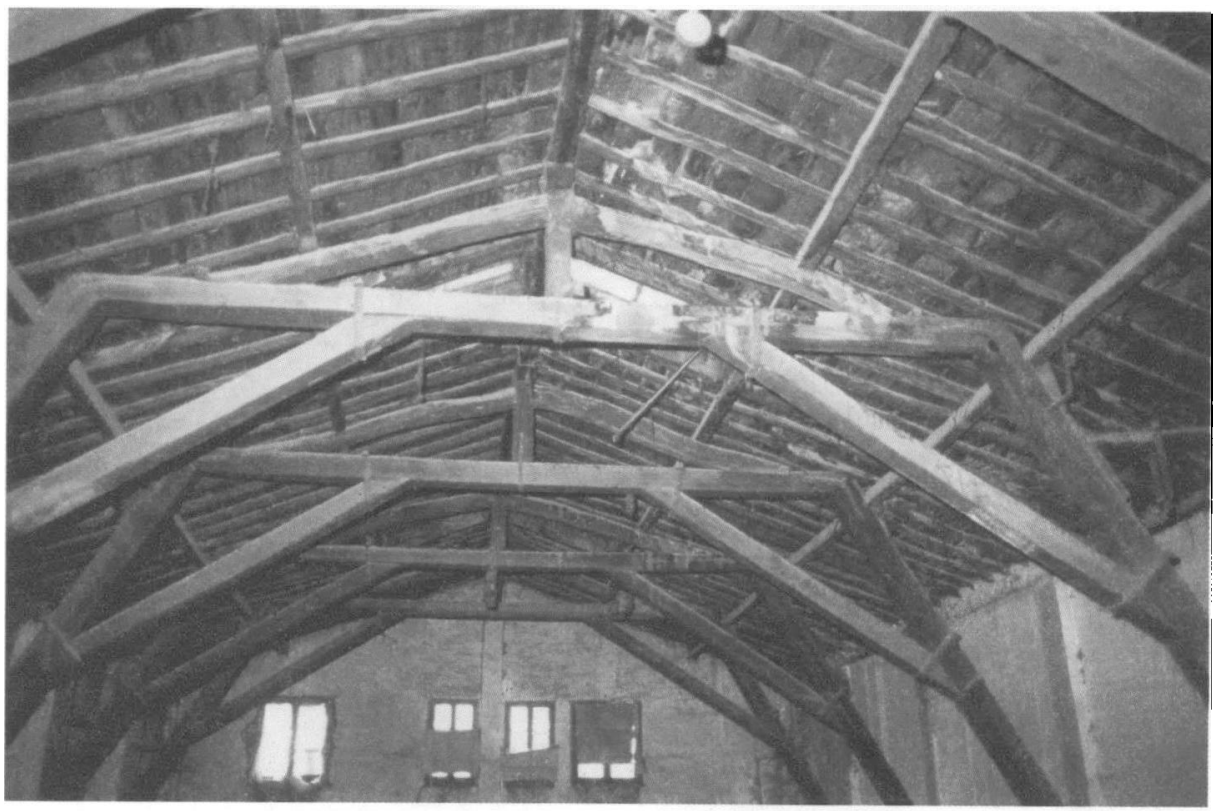

7.2. Techumbre de madera.

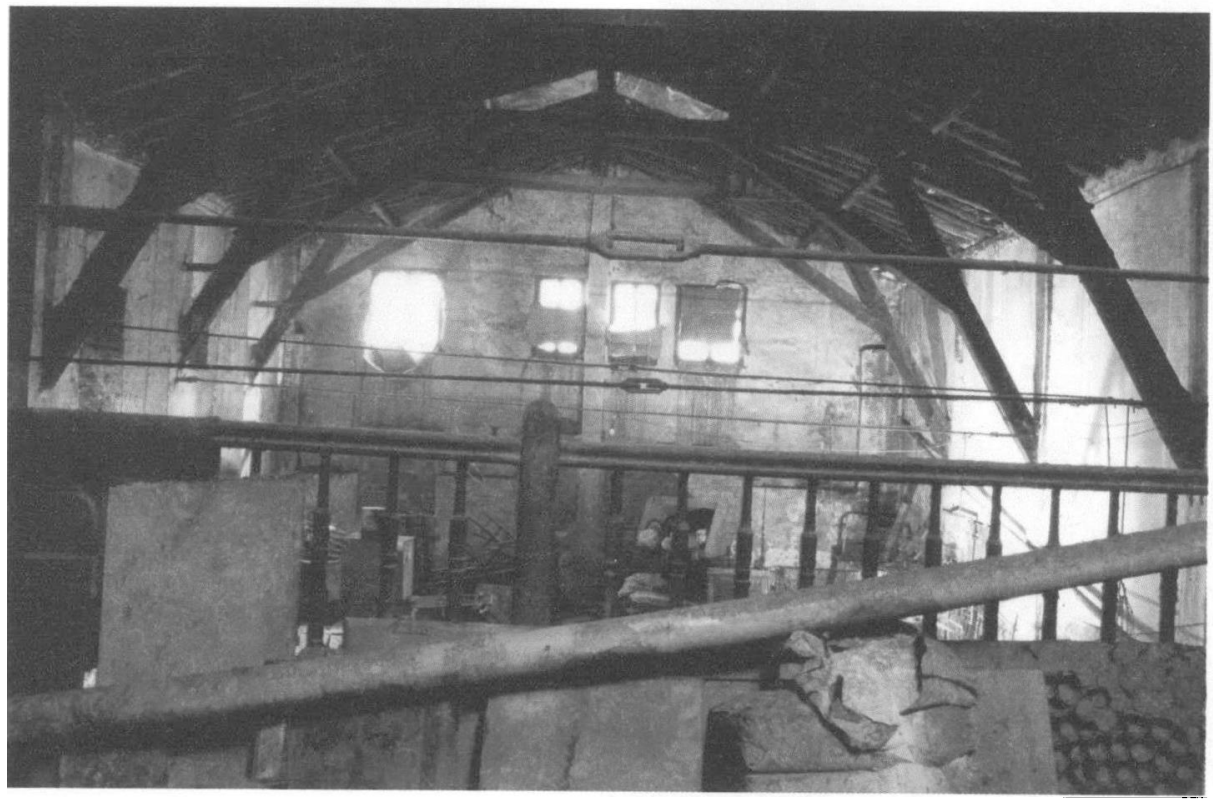

7.3. Detalle del muro sur. 
Julián Bravo Vega y Francisco Domínguez Matito

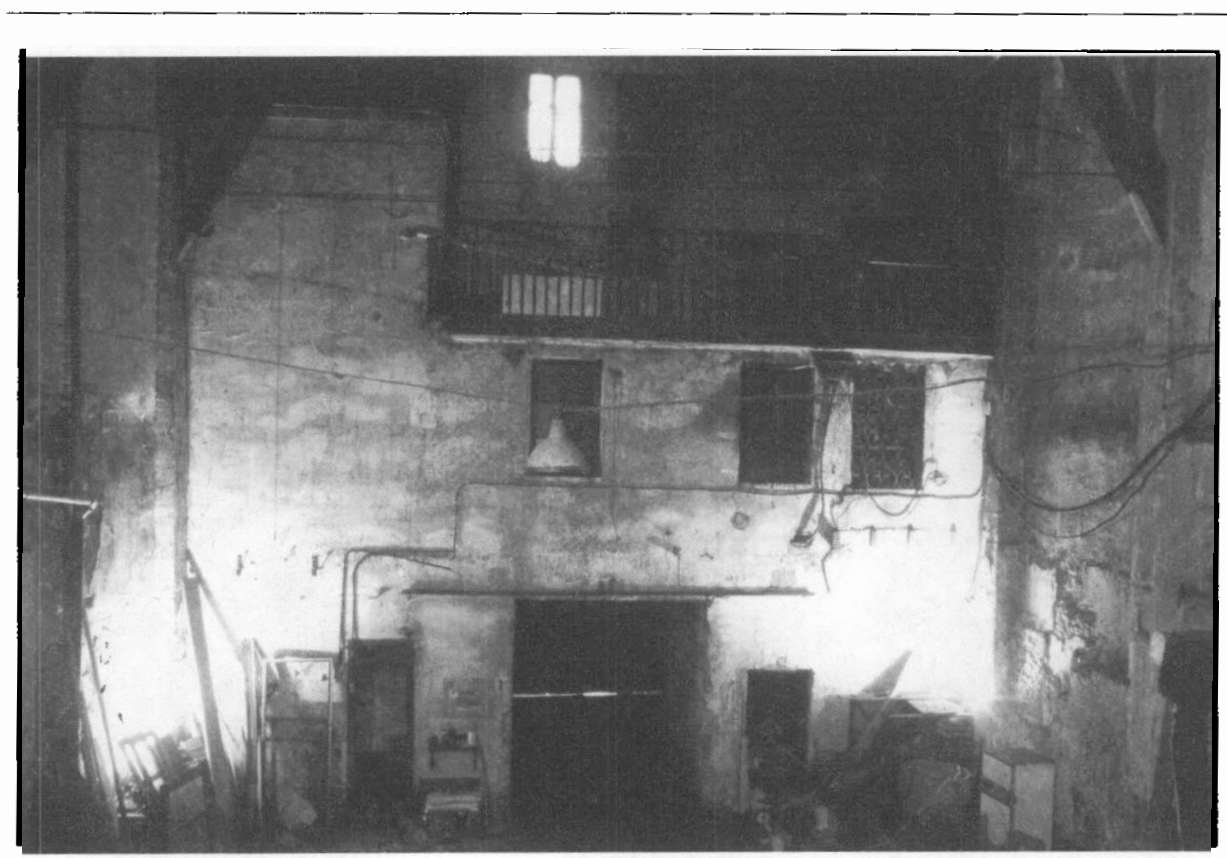

7.4. Detalle del muro norte. 